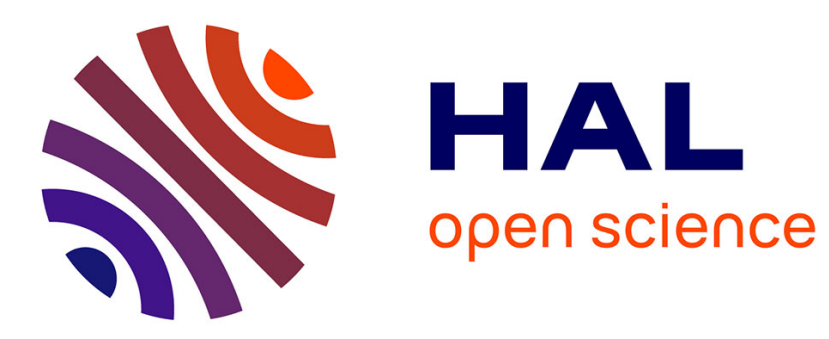

\title{
Disparities in cancer incidence by area-level socioeconomic status in the French West Indies
}

Danièle Luce, Stéphane Michel, Julien Dugas, B. Bhakkan, G. Menvielle, Clarisse Joachim, J. Deloumeaux

\section{- To cite this version:}

Danièle Luce, Stéphane Michel, Julien Dugas, B. Bhakkan, G. Menvielle, et al.. Disparities in cancer incidence by area-level socioeconomic status in the French West Indies. Cancer Causes and Control, 2017, 28 (11), pp.1305-1312. 10.1007/s10552-017-0946-3 . hal-01671494

HAL Id: hal-01671494

https://hal-univ-rennes1.archives-ouvertes.fr/hal-01671494

Submitted on 31 Jan 2020

HAL is a multi-disciplinary open access archive for the deposit and dissemination of scientific research documents, whether they are published or not. The documents may come from teaching and research institutions in France or abroad, or from public or private research centers.
L'archive ouverte pluridisciplinaire HAL, est destinée au dépôt et à la diffusion de documents scientifiques de niveau recherche, publiés ou non, émanant des établissements d'enseignement et de recherche français ou étrangers, des laboratoires publics ou privés. 
Disparities in cancer incidence by area-level socioeconomic status in the French West Indies

Danièle Luce ${ }^{1,2}$, Stéphane Michel ${ }^{3}$, Julien Dugas ${ }^{1,2}$, Bernard Bhakkan ${ }^{4}$, Gwenn Menvielle ${ }^{5}$, Clarisse Joachim ${ }^{6}$, Jacqueline Deloumeaux ${ }^{4}$

1. INSERM UMRS 1085-Institut de Recherche en Santé, Environnement et Travail (IRSET), Pointe-à-Pitre, Guadeloupe, France

2. University of Rennes 1

3. AMREC, Association Martiniquaise pour la Recherche Epidémiologique en Cancérologie, Fort-de-France, Martinique, France

4. Registre général des Cancers de Guadeloupe, Centre Hospitalier Universitaire de Guadeloupe, Pointe-à-Pitre, Guadeloupe, France

5. Sorbonne Universités, UPMC Univ Paris 06, INSERM, Institut Pierre Louis d'Épidémiologie et de Santé Publique (IPLESP UMRS 1136), Paris, France

6. Registre Général des cancers de la Martinique, UF 1441 Registre des cancers, Pôle de Cancérologie Hématologie Urologie Pathologie, CHU de Martinique, Fort-de-France, Martinique, France

\section{Corresponding author:}

Danièle Luce

INSERM U 1085 - IRSET

Faculté de Médecine

Campus de Fouillole

BP 145

F-97154 Pointe-à-Pitre

$\underline{\text { daniele.luce@inserm.fr }}$

\section{Acknowledgments}

This work was supported by the French National Cancer Institute (INCa).

\section{Ethical approval}

Commission Nationale de l'Informatique et des Libertés, French Data Protection Authority (CNIL authorization number DR-2013-193)

Conflict of Interest: The authors declare that they have no conflict of interest. 


\begin{abstract}
Purpose

Social inequalities in cancer incidence and mortality have been reported in France, but no data are available for the French overseas territories. Our objective was to explore the association between cancer incidence and the socioeconomic level of the residence area in the French West Indies.
\end{abstract}

\title{
Methods
}

Cancer incidence data were obtained from the cancer registries of Guadeloupe and Martinique (2009-2010). To assess socioeconomic status, we developed a specific index of social deprivation from census data at a small-area level. We used Bayesian methods to evaluate the association between cancer incidence and the deprivation index, for all cancers combined and for the major cancer sites.

\section{Results}

There was no clear association between area-based deprivation and the incidence of all cancers combined. In men, higher area deprivation was associated with a higher incidence of prostate cancer (relative risk (RR) 1.25, 95\% credible interval (CI) 1.04-1.49; RR 1.08, CI 0.91-1.29 in the categories of intermediate and high deprivation respectively, compared to low deprivation), but was not associated with respiratory cancer. Women living in the most deprived areas had a higher incidence of stomach (RR 1.77, CI 1.12-2.89), breast (RR 1.15, CI 0.90-1.45) and cervix (RR 1.13, CI 0.63-2.01) cancers and a lower incidence of respiratory cancer (RR 0.65, CI 0.38-1.11).

\section{Conclusion}

These first results in the French West Indies suggest specific patterns for some cancer sites that warrant to be further investigated.

Keywords: Cancer incidence; socioeconomic status; social deprivation index; French West Indies 


\section{Introduction}

Social inequalities in cancer incidence and mortality have been reported in all developed countries [1, 2]. Social differences in cancer mortality are particularly large in France [3, 4] and recent studies have also provided evidence of social inequalities in cancer incidence [5, 6]. However, these results are limited to mainland France, and no information on social determinants of cancer is currently available in French overseas territories, whereas socioeconomic inequalities in these regions are stronger than in the mainland. Documenting and monitoring social inequalities in cancer incidence is an essential element of public health surveillance.

Guadeloupe and Martinique are two French overseas regions in the French West Indies (FWI), with a population of about 400,000 in each territory. The vast majority of the population, about $85 \%$, is Afro-Caribbean. These regions experienced rapid economic growth in the last 30 years, but the gross domestic product per capita is still about $65 \%$ of the national average. When compared to the national average, the population of the FWI is characterized by a lower median income, larger income inequalities, a lower educational level, a higher rate of unemployment, and a larger proportion of people who get income support. The population benefits from the health insurance system of the French population, which in principle guarantees universal access to care. Cancer epidemiology has also some specific features. Cancer incidence is globally lower than in mainland France, but is higher for prostate, stomach and cervical cancers. In contrast, lung cancers and upper aero-digestive tracts, which in France contribute strongly to social inequalities in cancer, have much lower incidence rates in the FWI. In general, cancer incidence rates in the FWI are between those of mainland France and those of the other countries in the Caribbean [7]. Because of this specific social, economic and epidemiological context, studies on social inequalities in cancer incidence in these regions are of particular interest.

Cancer registries were implemented in Martinique (since 1983) and in Guadeloupe (since 2008). Cancer registries do not routinely collect data on socioeconomic status at the individual level, but record the address of residence, making it possible to use area-based measures of socioeconomic status. Our objective was to assess the feasibility to describe social inequalities in cancer incidence in the FWI, using cancer registries data and the socioeconomic level of the residence area.

\section{Material and Methods}




\section{Population data}

The French National Institute for Statistics and Economic Studies (Institut National de la Statistique et des Etudes Economiques, INSEE) provides census data for each year since 2006. Aggregated data are available for a number of social, demographic and economic indicators, at a sub-municipality level, the IRIS level (for Ilots regroupés pour l'information statistique; Merged Islet for Statistical Information). The IRIS is the smallest geographical census unit available in France. There are 141 IRIS in Martinique and 136 IRIS in Guadeloupe.

\section{Cancer incidence}

The study included all cancer cases diagnosed between January 1, 2009 and December 31, 2010 recorded in the cancer registries of Guadeloupe and Martinique (5618 cases). Available information for each cancer case include sex, age at diagnosis, cancer site (coded with the International Classification of Diseases for Oncology, third edition; ICD-O-3) and address of residence. The addresses were geocoded to assign the IRIS of residence.

\section{Construction of the deprivation index}

Deprivation indices, composite indices using several variables to characterize the socioeconomic level of the residence area, are often used to describe social inequalities in health. Several indices of deprivation have been recently developed for mainland France [810], but are poorly suited to the Caribbean context. Some variables used in these indices are not available or may have different meanings. For example, access to heating [10] is not collected in the FWI for obvious reasons; the median income [8, 9] is not available at a small area level in Guadeloupe; the proportion of non-owner-occupied primary residences $[8,10]$ has a different connotation in the Caribbean, where low-income households own their residence as frequently as the others. Therefore, we first developed a specific index of neighbourhood deprivation, suitable for the FWI.

The deprivation index was constructed from data of the 2008 French national census, at the IRIS level. The data for the two regions, Guadeloupe and Martinique, were pooled. First, a priori selection of 137 variables representing different census domains was carried out. Several principal component analyses were used to select the variables most correlated to the first component and contributing most to its construction. Finally, eight variables covering different dimensions of deprivation were selected: proportion of unemployed, proportion of blue-collar workers, proportion of managers, proportion of salaried employees on permanent contract (employment); proportion of people without any diploma (education); proportion of 
households with no car (equipment); proportion of primary residences with hot water, proportion of primary residences with air conditioning (housing). The deprivation index was defined as the first component of a principal component analysis of these eight variables. This first component explained $62 \%$ of the total variance, while the second component accounted for only $10.1 \%$ of the total variation. To check the robustness of our results, we re-run the analyses in each region separately. These analyses lead to the selection of the same variables, with similar coefficients. We calculated the index for each IRIS. To evaluate the index validity, we calculate the Cronbach's alpha coefficient and we examined the correlations between the index and the variables used in its construction (internal validity). External validity was assessed by the correlation coefficients between our index and two widely used deprivation indices (indices of Townsend [11] and Carstairs [12]). We were not able to calculate previously developed French deprivation indices [8-10] or other recent indices (e.g. $[13,14])$ because some variables were not available in the FWI. We then used hierarchical clustering to group the IRIS in three categories of low, medium and high deprivation.

\section{Association between cancer incidence and area deprivation}

Analyses were conducted for all cancer sites, and for cancer of the prostate (ICD-O3 code C61), breast (C50), colon-rectum (C18-C21), stomach (C16), cervix (C53), lung (C33-34) and upper aero-digestive tract (C00-C14, C32). Due to the small number of cases, cancers of the lung, oral cavity, pharynx and larynx were grouped in the analysis. Analyses stratified by sex were also performed. The population at-risk was obtained from census data in 2009 and 2010, which provide for each IRIS the population by sex and age group $(<15$ years, 15-29 years, 3044 years, 45-59 years, 60-74 years, $>=75$ years).

We estimated standardized incidence ratios (SIRs) with Bayesian modelling to take into account extra-Poisson variability. These models in their general form consider the expected cases as an offset and allow for overdispersion by including two types of random effects: unstructured (non-spatial) random effects and spatially structured random effects [15]. These models enable to obtain smoothed estimates of the SIR, that overcome limitations related to SIR mapping in small geographical areas [16]. The number of expected cases in each IRIS was calculated via indirect standardization for age and sex, using overall age and sex specific incidence rates in each region as reference rates. For each cancer site, to choose the model that best fitted the data, we first tested the presence of unstructured heterogeneity using the Potthoff-Whittinghill test [17], and the presence of spatial autocorrelation with the Empirical Bayes Index (EBI) [18], more powerful than the classic Moran's I statistics. The Potthoff- 
Whittinghill test was significant for all the studied cancer sites. On the contrary, none of the EBIs was statistically significant. As there was no spatial autocorrelation in our data, we chose to use models that included only the unstructured (non-spatial) heterogeneity. As a check, we also fitted models including both types of random effects (unstructured heterogeneity and spatial autocorrelation) and examined the relative contribution to each component to overdispersion. Unstructured random effect dominates the spatially structured random effect in all models. We also used the Deviance Information Criteria (DIC) to compare models including only the unstructured heterogeneity component and models including both unstructured and spatially structured random effects, the smallest DIC indicating the better fit. For all the cancer sites, the addition of the spatial component lead to higher or similar DICs, i.e. did not improve the fit.

To study the association between cancer incidence and deprivation, deprivation categories were introduced in the model as two dummy variables for the medium and high deprivation categories, the least deprived category being set as the reference group. The relative risk (RR) estimates were obtained based on their posterior means, along with the corresponding $95 \%$ credible intervals (95\%CI), using Markov Chain Monte Carlo algorithms. For each model we ran two independent chains of 30000 iterations after a burn-in of 30000 iterations.

Bayesian analyses were performed using R 3.3.2, with R2WinBUGS package, interfacing Winbugs and R, spdep package for calculation of the EBIs and DCluster package for the Pottwhoff-Whittinghill tests. All other analyses were conducted using SAS 9.3.1 (SAS Institute, Cary NC).

\section{Results}

The deprivation index varied from -3.61 (in the less deprived census tract) to 2.23 (in the most deprived). The internal consistency was satisfactory (Cronbach's alpha coefficient $=0.87$ ). The deprivation index was positively correlated with the indices of Carstairs $(r=0.82, p<0,001)$ and Townsend $(\mathrm{r}=0.52, \mathrm{p}<0.001)$. The weaker correlation with the Townsend index is due to the inclusion in this index of non-home ownership, which, as explained above, is not very relevant to deprivation in the FWI. The index was strongly and significantly correlated with the variables used for its construction (Table 1), in the expected direction: positively with the proportion of unemployed, uneducated, manual workers, households with no car, negatively with the proportion of stable jobs, managers, residences with hot water and air conditioning. Table 1 also shows the mean values of the index and of each variable in the three categories of deprivation used in the analyses, which exhibit gradual increases or decreases consistent 
with deprivation. The geographical distribution of the deprivation index is shown in Figures 1a and $1 \mathrm{~b}$ for Guadeloupe and Martinique, respectively. The most deprived areas are mainly located in in the north and west of Guadeloupe, and in the northeast of Martinique.

Smoothed SIRs for all cancers combined are mapped for Guadeloupe and Martinique in Figures 2a and 2b. Maps for the studied cancer sites are available in Supplementary material (Figures 3-8).

The association between cancer incidence and deprivation is shown in table 2. No clear association was found for the incidence of all cancers combined. For prostate cancer, which account for more than half of all male cancer cases, the incidence was significantly higher in the category of medium deprivation than in the least deprived category (RR: $1.25,95 \% \mathrm{CI}$ : $1.04 ; 1.49)$. The RR decreased in the most deprived category, but remains higher than 1 , although non-significant (RR: 1.08, 95\% CI: 0.91; 1.29). The incidence of breast cancer increased slightly and non-significantly with deprivation, with an RR of 1.15 (95\% CI: 0.90; $1.45)$ in the more deprived category. No association was observed between the incidence of colorectal cancer and the level of deprivation of the residence area. Stomach cancer incidence increased with area deprivation. The association was stronger in women than in men, and significant in women only, with a RR of 1.77 (95\% CI: 1.12; 2.89) in the most deprived category. The numbers of cases of cancer of the cervix, upper aero-digestive tract and lung were small and no significant association was found. However, there was some indication of an increase in risk of cervical cancer with increasing area deprivation. Conversely, the risk of respiratory cancer seems to decrease in the most deprived category, particularly in women (RR: 0.64, 95\% CI: 0.38; 1.11).

\section{Discussion}

This study assessed for the first time socioeconomic inequalities in the French West Indies, using an indicator of deprivation at a small-area level. Overall, we found little evidence of social inequalities in cancer incidence. Nevertheless, these preliminary results evidenced specific patterns for some cancer sites.

Social inequalities in cancer incidence result from complex interactions between access to health care, utilization of screening and risk factors. Our objective is essentially descriptive, and a full discussion of the pathways and mechanisms is beyond the scope of this study. Rather, results should be used as a starting point to more in-depth studies. However, our findings may be compared to previous studies and some possible explanations may be mentioned. 
We found a higher risk of prostate cancer in the category of medium deprivation, and overall the lowest incidence of prostate cancer was observed in the least deprived category. A number of studies, using individual or area-based indicators of social position, reported a higher risk in those with a high socioeconomic status [6, 19-21], although other found no or negative associations, especially among African American men [22, 23]. The high incidence in the most favored groups is generally attributed to a higher rate of screening, leading to the detection of indolent cases and overdiagnosis. The incidence of prostate cancer is very high in the FWI, and it is possible that screening practices differ in these high-risk populations.

We found no significant association between deprivation and breast cancer incidence. Most studies, but not all, reported a higher risk of breast cancer in women with high socioeconomic status, or living in areas with high socioeconomic level [24, 25]. This relation is generally explained by the distribution of reproductive risk factors by socioeconomic status. Our results, although non-significant, pointed in the opposite direction, that is a higher incidence of breast cancer in the most deprived areas. In the US, the positive gradient with socioeconomic status is less consistently reported among African American women, some studies reporting a weak negative gradient [25]. Recent studies have also suggested that socioeconomic status would not be associated with hormone receptor negative tumors [26, 27]. There is some evidence of a high proportion of hormone receptor negative tumors in the FWI, as in other populations of African descent [28].

Our finding of an increased incidence of stomach cancer in the most deprived areas is consistent with previous studies [29]. Infection with Helicobacter pylori, a major risk factor of stomach cancer, is strongly related to socioeconomic status. Other risk factors include smoking, alcohol consumption and dietary factors [30]. In our data, the association seems to be limited to women. Given the small number of cases, this could be due to chance or may reflect real gender differences in risk factors and/or in their social distribution.

The lack of association between deprivation and the incidence of lung and aero-digestive tract cancers contrasts with the results observed in mainland France [6] and in almost all developed countries, where these cancers exhibit the strongest social inequalities[31, 32]. Furthermore, we found some indications of a negative association with deprivation, with a decreased risk in the most deprived areas, more evident among women. Similar results were also found in populations at the earlier stages of the smoking epidemic[33, 34]. Social inequalities in respiratory cancer incidence are largely explained by the social distribution of smoking habits. Recent data from a health survey conducted in the FWI have shown that, in this population 
with an overall low smoking prevalence, smoking is more frequent in the most favored categories, particularly among women (Baromètre Santé DOM, unpublished data).

Screening for colorectal and cervical cancer led to removing of precancerous lesions, thus preventing an invasive cancer. A slightly higher screening rate of colorectal and cervical cancer screening in the most favored people was reported in the FWI [35]. In the present study, we found no association between deprivation and colorectal cancer incidence. In the literature, no clear pattern emerged for the relationship between socioeconomic status and colorectal cancer risk, studies showing either a higher (mainly in the US) or a lower (mainly in Europe) incidence in those with low socioeconomic status [36]. For cervical cancer, in our study, despite a slight non-significant increase with deprivation, the small numbers of cases do not allow to reach a conclusion.

We developed a specific index of deprivation, adapted to the local context. This composite index takes into account different dimensions of deprivation, and better reflects the complexity of deprivation than a single indicator. The index was constructed from principal component analysis of census data, a widely used approach for developing such indices[8, 9, 13, 14, 37]. Internal and external validation (correlations between the index and its components, Cronbach's alpha, correlations with other indices) was satisfactory. Associations between cancer incidence and the deprivation index, even if some of them are unusual, have plausible explanations in this population. We are therefore confident that our deprivation index is appropriate to capture social inequalities in health in the FWI. A weakness of our approach however is that some of the IRIS in the FWI are relatively large, and then probably heterogeneous with regards to socioeconomic level. Also, an inherent limitation to this type of ecological analyses is that we were not able to separate the effects of neighborhood (true contextual effects) to the effects of individual socioeconomic status. We have collected data at an individual level for a subsample of cases. Further analyses taking into account both individual socioeconomic status and the deprivation level of the residence area may help interpret the findings.

The main limitation of the present study is the small number of cases and the consequent lack of statistical power. The analysis was restricted to cases recorded in 2009 and 2010, as not all cases were geocoded at the IRIS level for the other years. However, these preliminary results demonstrate that the approach we used is feasible in the FWI and revealed specific patterns regarding socioeconomic inequalities in cancer incidence in this population. Work is ongoing to complete the geocoding in the cancer registries databases. Subsequent analyses taking 
account a longer period of incidence will include a larger number of cases and will allow to confirm or infirm some of the suggested associations. At a later stage, it will be possible to evaluate time trends in social inequalities in cancer incidence. Finally, cancer registries data and the deprivation index will be also used to document social inequalities in cancer survival and management, in order to provide a comprehensive picture of social inequalities and cancer in the FWI and to help define effective strategies to reduce these inequalities. 


\section{References}

1. Faggiano F, Partanen T, Kogevinas M, Boffetta P (1997) Socioeconomic differences in cancer incidence and mortality. IARC Sci Publ 65-176.

2. Merletti F, Galassi C, Spadea T (2011) The socioeconomic determinants of cancer. Environ Health Glob Access Sci Source 10 Suppl 1:S7. doi: 10.1186/1476-069X-10-S1S7

3. Menvielle G, Rey G, Jougla E, Luce D (2013) Diverging trends in educational inequalities in cancer mortality between men and women in the 2000s in France. Bmc Public Health 13:823. doi: 10.1186/1471-2458-13-823

4. Toch-Marquardt M, Menvielle G, Eikemo TA, et al (2014) Occupational class inequalities in all-cause and cause-specific mortality among middle-aged men in 14 European populations during the early 2000s. PloS One 9:e108072. doi: 10.1371/journal.pone.0108072

5. Bryere J, Dejardin O, Bouvier V, et al (2014) Socioeconomic environment and cancer incidence: a French population-based study in Normandy. BMC Cancer 14:87. doi: 10.1186/1471-2407-14-87

6. Bryere J, Dejardin O, Launay L, et al (2016) Socioeconomic status and site-specific cancer incidence, a Bayesian approach in a French Cancer Registries Network study. Eur J Cancer Prev. doi: 10.1097/CEJ.0000000000000326

7. Ferlay J, Soerjomataram I, Ervik M, et al (2013) GLOBOCAN 2012 v1.0, Cancer Incidence and Mortality Worldwide: IARC CancerBase No. 11. In: Int. Agency Res. Cancer. http://globocan.iarc.fr. Accessed 30 May 2017

8. Havard S, Deguen S, Bodin J, et al (2008) A small-area index of socioeconomic deprivation to capture health inequalities in France. Soc Sci Med 1982 67:2007-2016. doi: 10.1016/j.socscimed.2008.09.031

9. Rey G, Jougla E, Fouillet A, Hémon D (2009) Ecological association between a deprivation index and mortality in France over the period 1997 - 2001: variations with spatial scale, degree of urbanicity, age, gender and cause of death. BMC Public Health 9:33. doi: 10.1186/1471-2458-9-33

10. Pornet C, Delpierre C, Dejardin O, et al (2012) Construction of an adaptable European transnational ecological deprivation index: the French version. J Epidemiol Community Health 66:982-989. doi: 10.1136/jech-2011-200311

11. Townsend P (1987) Deprivation. J Soc Policy 16:125-146. doi: 10.1017/S0047279400020341

12. Carstairs V, Morris R (1989) Deprivation: explaining differences in mortality between Scotland and England and Wales. BMJ 299:886-889.

13. Messer LC, Laraia BA, Kaufman JS, et al (2006) The Development of a Standardized Neighborhood Deprivation Index. J Urban Health Bull N Y Acad Med 83:1041-1062. doi: $10.1007 / \mathrm{s} 11524-006-9094-\mathrm{x}$ 
14. Pampalon R, Hamel D, Gamache P, et al (2012) An area-based material and social deprivation index for public health in Québec and Canada. Can J Public Health Rev Can Sante Publique 103:S17-22.

15. Besag J, York J, Mollié A (1991) Bayesian image restoration, with two applications in spatial statistics. Ann Inst Stat Math 43:1-20. doi: 10.1007/BF00116466

16. Lawson AB, Biggeri AB, Boehning D, et al (2000) Disease mapping models: an empirical evaluation. Disease Mapping Collaborative Group. Stat Med 19:2217-2241.

17. Potthoff RF, Whittinghill M (1966) Testing for homogeneity. I. The binomial and multinomial distributions. Biometrika 53:167-182.

18. Assunção RM, Reis EA (1999) A new proposal to adjust Moran's I for population density. Stat Med 18:2147-2162.

19. Cheng I, Witte JS, McClure LA, et al (2009) Socioeconomic status and prostate cancer incidence and mortality rates among the diverse population of California. Cancer Causes Control 20:1431. doi: 10.1007/s10552-009-9369-0

20. Hastert TA, Beresford SAA, Sheppard L, White E (2015) Disparities in cancer incidence and mortality by area-level socioeconomic status: a multilevel analysis. J Epidemiol Community Health 69:168-176. doi: 10.1136/jech-2014-204417

21. Garcia-Gil M, Elorza J-M, Banque M, et al (2014) Linking of Primary Care Records to Census Data to Study the Association between Socioeconomic Status and Cancer Incidence in Southern Europe: A Nation-Wide Ecological Study. PLoS ONE. doi: 10.1371/journal.pone.0109706

22. Major JM, Oliver MN, Doubeni CA, et al (2012) Socioeconomic status, health care density, and risk of prostate cancer among African-American and Caucasian men in a large prospective study. Cancer Causes Control CCC 23:1185-1191. doi: $10.1007 / \mathrm{s} 10552-012-9988-8$

23. Sanderson M, Coker AL, Perez A, et al (2006) A Multilevel Analysis of Socioeconomic Status and Prostate Cancer Risk. Ann Epidemiol 16:901-907. doi: 10.1016/j.annepidem.2006.02.006

24. Klassen AC, Smith KC (2011) The enduring and evolving relationship between social class and breast cancer burden: A review of the literature. Cancer Epidemiol 35:217234. doi: 10.1016/j.canep.2011.02.009

25. Akinyemiju TF, Genkinger JM, Farhat M, et al (2015) Residential environment and breast cancer incidence and mortality: a systematic review and meta-analysis. BMC Cancer. doi: 10.1186/s12885-015-1098-Z

26. Palmer JR, Boggs DA, Wise LA, et al (2012) Individual and Neighborhood Socioeconomic Status in Relation to Breast Cancer Incidence in African-American Women. Am J Epidemiol 176:1141-1146. doi: 10.1093/aje/kws211 
27. Akinyemiju TF, Pisu M, Waterbor JW, Altekruse SF (2015) Socioeconomic status and incidence of breast cancer by hormone receptor subtype. SpringerPlus 4:508. doi: 10.1186/s40064-015-1282-2

28. Deloumeaux J, Gaumond S, Bhakkan B, et al (2017) Incidence, mortality and receptor status of breast cancer in African Caribbean women: Data from the cancer registry of Guadeloupe. Cancer Epidemiol 47:42-47. doi: 10.1016/j.canep.2017.01.004

29. Uthman OA, Jadidi E, Moradi T (2013) Socioeconomic position and incidence of gastric cancer: a systematic review and meta-analysis. J Epidemiol Community Health 67:854860. doi: 10.1136/jech-2012-201108

30. Karimi P, Islami F, Anandasabapathy S, et al (2014) Gastric cancer: descriptive epidemiology, risk factors, screening, and prevention. Cancer Epidemiol Biomark Prev Publ Am Assoc Cancer Res Cosponsored Am Soc Prev Oncol 23:700-713. doi: 10.1158/1055-9965.EPI-13-1057

31. Sidorchuk A, Agardh EE, Aremu O, et al (2009) Socioeconomic differences in lung cancer incidence: a systematic review and meta-analysis. Cancer Causes Control CCC 20:459-471. doi: 10.1007/s10552-009-9300-8

32. Conway DI, Brenner DR, McMahon AD, et al (2015) Estimating and explaining the effect of education and income on head and neck cancer risk: INHANCE consortium pooled analysis of 31 case-control studies from 27 countries. Int J Cancer 136:11251139. doi: 10.1002/ijc. 29063

33. Antunes JLF, Borrell C, Rodríguez-Sanz M, et al (2008) Sex and socioeconomic inequalities of lung cancer mortality in Barcelona, Spain and São Paulo, Brazil: Eur J Cancer Prev 17:399-405. doi: 10.1097/CEJ.0b013e3282f75f17

34. Wong ML, Clarke CA, Yang J, et al (2013) Incidence of non-small-cell lung cancer among California Hispanics according to neighborhood socioeconomic status. J Thorac Oncol Off Publ Int Assoc Study Lung Cancer 8:287-294. doi: 10.1097/JTO.0b013e31827bd7f5

35. Menvielle G, Dugas J, Richard J-B, Luce D (2016) Socioeconomic and healthcare userelated determinants of cervical, breast and colorectal cancer screening practice in the French West Indies. Eur J Cancer Prev Off J Eur Cancer Prev Organ ECP. doi: 10.1097/CEJ.0000000000000329

36. Aarts MJ, Koldewijn EL, Poortmans PM, et al (2013) The impact of socioeconomic status on prostate cancer treatment and survival in the southern Netherlands. Urology 81:593-599. doi: 10.1016/j.urology.2012.11.011

37. Salmond CE, Crampton P (2012) Development of New Zealand's deprivation index (NZDep) and its uptake as a national policy tool. Can J Public Health Rev Can Sante Publique 103:S7-11. 
Table 1. Descriptive statistics of the deprivation index and its components

\begin{tabular}{|c|c|c|c|c|}
\hline & & \multicolumn{3}{|c|}{ Deprivation category } \\
\hline & & Low & Medium & High \\
\hline Number of IRIS & & 77 & 96 & 104 \\
\hline Population & & 260834 & 271575 & 267070 \\
\hline Variables $^{\mathrm{a}}$ & Correlation $^{\mathrm{b}}$ & \multicolumn{3}{|c|}{ Mean per category } \\
\hline Unemployed & 0.816 & 20.12 & 27.3 & 34.63 \\
\hline Blue-collar workers & 0.797 & 13.73 & 20.33 & 26.63 \\
\hline Managers & -0.882 & 8.08 & 3.45 & 1.72 \\
\hline Permanent contracts & -0.617 & 84.79 & 81.39 & 77.24 \\
\hline No educated & 0.882 & 26.57 & 38.71 & 50.99 \\
\hline Households with no car & 0.713 & 21.89 & 32.6 & 41.99 \\
\hline Primary residences with hot water & -0.839 & 72.17 & 57.08 & 46.59 \\
\hline Primary residences with air conditioning & -0.665 & 34.57 & 22.09 & 13.75 \\
\hline Deprivation index & & -1.28 & -0.03 & 0.97 \\
\hline
\end{tabular}

a. All variables are percentages

b. Correlation with the deprivation index 
Table 2. Association between social deprivation of the residence area and cancer incidence

\begin{tabular}{|c|c|c|c|c|c|c|c|}
\hline \multirow[b]{3}{*}{ Cancer site } & \multirow[b]{3}{*}{ Sex } & \multicolumn{6}{|c|}{ Deprivation category } \\
\hline & & \multicolumn{2}{|r|}{ Low } & \multicolumn{2}{|r|}{ Medium } & \multicolumn{2}{|r|}{ High } \\
\hline & & $\mathbf{N}$ & RR $[95 \%$ CI $]$ & $\mathbf{N}$ & RR $[95 \% \mathrm{CI}]$ & $\mathbf{N}$ & RR $[95 \% \mathrm{CI}]$ \\
\hline \multirow[t]{3}{*}{ All cancers } & men+women & 1664 & 1 [ref.] & 1959 & $1.11[0.94 ; 1.31]^{\mathrm{c}}$ & 1995 & $1.04[0.88 ; 1.22]$ \\
\hline & men & 993 & 1 [ref.] & 1171 & $1.11[0.95 ; 1.31]$ & 1185 & $1.00[0.86 ; 1.18]$ \\
\hline & women & 671 & 1 [ref.] & 788 & $1.10[0.91 ; 1.32]$ & 810 & $1.08[0.90 ; 1.30]$ \\
\hline Prostate & men & 480 & 1 [ref.] & 646 & $1.25[1.04 ; 1.49]$ & 624 & $1.08[0.91 ; 1.29]$ \\
\hline Breast & women & 220 & 1 [ref.] & 239 & $1.04[0.82 ; 1.32]$ & 264 & $1.15[0.90 ; 1.45]$ \\
\hline \multirow[t]{3}{*}{ Colon-rectum } & men+women & 198 & 1 [ref.] & 219 & $1.00[0.78 ; 1.29]$ & 213 & $0.91[0.71 ; 1.16]$ \\
\hline & men & 107 & 1 [ref.] & 114 & $0.97[0.71 ; 1.31]$ & 107 & $0.81[0.59 ; 1.10]$ \\
\hline & women & 91 & 1 [ref.] & 105 & $1.07[0.78 ; 1.49]$ & 106 & $1.00[0.73 ; 1.39]$ \\
\hline \multirow[t]{3}{*}{ Stomach } & men+women & 78 & 1 [ref.] & 110 & $1.27[0.92 ; 1.75]$ & 129 & $1.31[0.96 ; 1.78]$ \\
\hline & men & 48 & 1 [ref.] & 55 & $1.04[0.70 ; 1.57]$ & 63 & $1.03[0.70 ; 1.54]$ \\
\hline & women & 30 & 1 [ref.] & 55 & $1.64[1.01 ; 2.68]$ & 66 & $1.77[1.12 ; 2.89]$ \\
\hline Cervix & women & 28 & 1 [ref.] & 31 & $1.06[0.60 ; 1.87]$ & 35 & $1.13[0.63 ; 2.01]$ \\
\hline Lung/Upper aerodigestive & men+women & 124 & 1 [ref.] & 143 & $1.11[0.84 ; 1.46]$ & 114 & $0.81[0.61 ; 1.09]$ \\
\hline \multirow[t]{2}{*}{ tract } & men & 87 & 1 [ref.] & 101 & $1.13[0.81 ; 1.60]$ & 86 & $0.88[0.62 ; 1.26]$ \\
\hline & women & 48 & 1 [ref.] & 55 & $1.04[0.64 ; 1.72]$ & 63 & $0.65[0.38 ; 1.11]$ \\
\hline
\end{tabular}

$\mathrm{N}$ : Number of cases; RR: relative risk, Bayesian modelling after standardization for age and sex; 95\%CI: 95\% Bayes credible interval 
Figure 1. Mapping of the deprivation index. Figure 1a: Guadeloupe; Figure 1b: Martinique

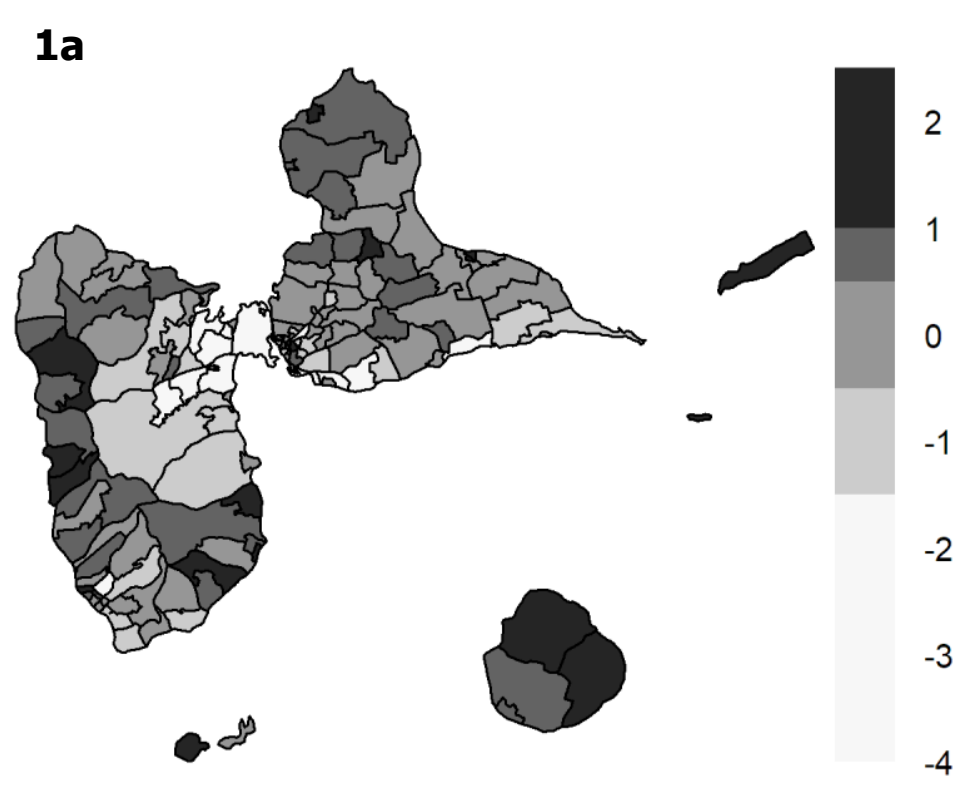

$1 \mathbf{b}$

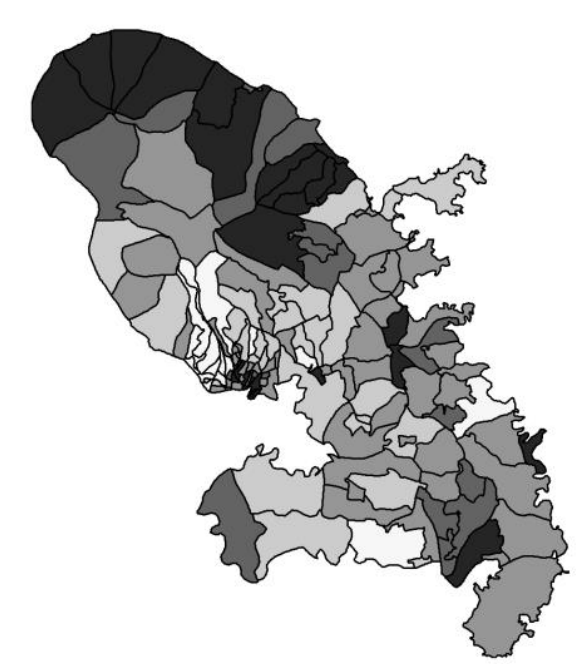


Figure 2. Standardized incidence ratios of all cancers combined. Figure 2a: Guadeloupe; Figure 2b: Martinique

$2 a$

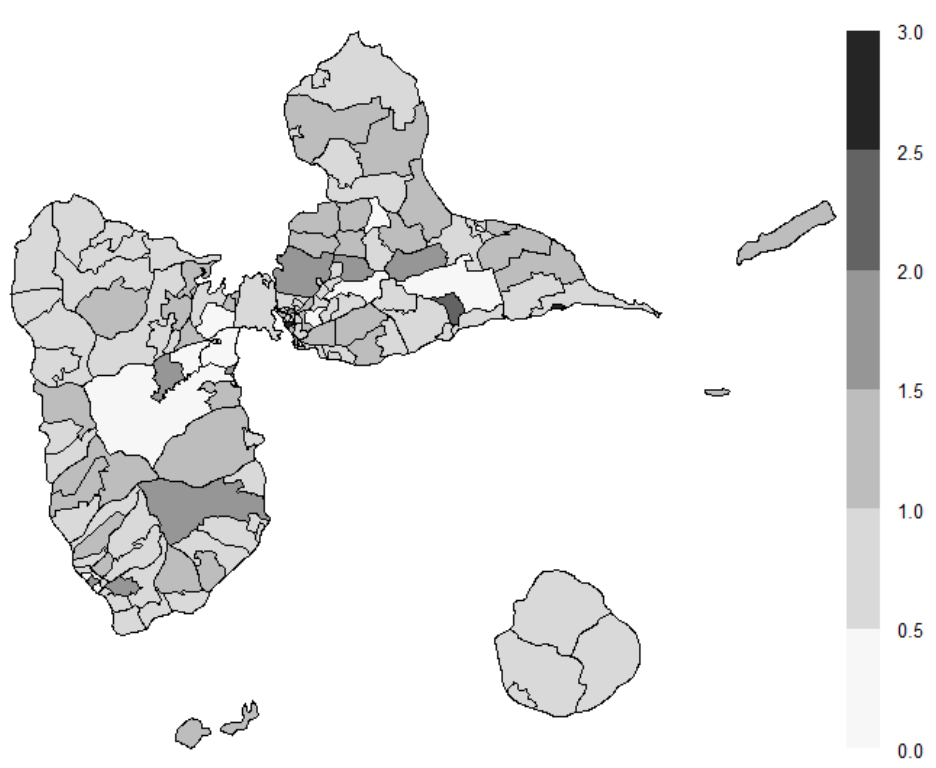

2b

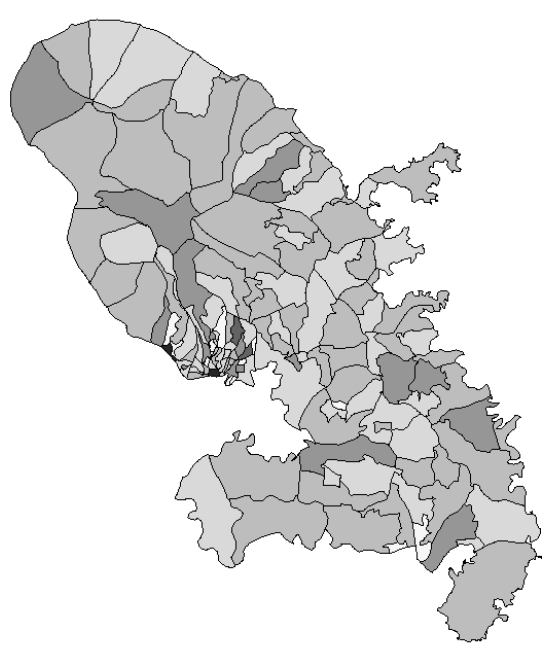

